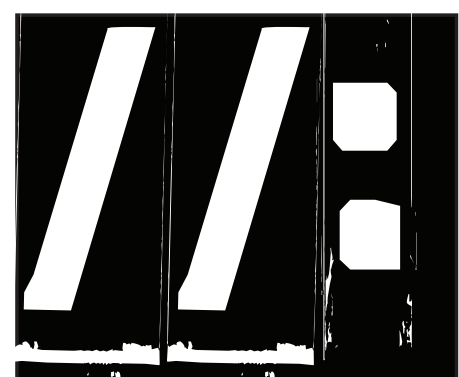

educa”ción y co"municación 10:143-145 Mayo 2015
"EDUCACIÓN PARA UNA GIUDADANÍA INTERCULTURAL"

Autores: CRISTINA GOENECHEA PERMISÁN Y RAFAEL ÁNGEL JIMÉNEZ GÁMEZ.

Añ̃o: 2014

Editorial: Síntesis

Localidad: Madrid

Por Michel Santiago del Pino

(Grupo de Investigación: Investigacion Educativa

"Eduardo Benot" (HUM 230)

Facultad de Ciencias de la Educación.

Universidad de Cádiz (España))

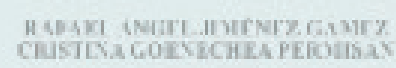

Iiduc:ac:icin

PARA INA CIIIDADAVÍa

INTERC ULTURAL

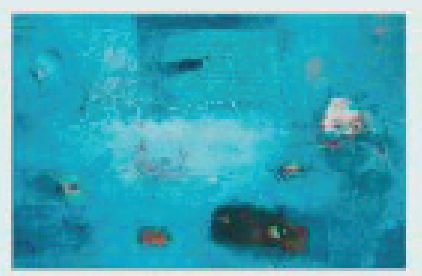


$\mathrm{N}_{\mathrm{n}}^{\circ}$ vamos a abundar aquí en los desastres económico-sociales que ha traído a nuestro país el tratamiento dado a la 'crisis' por el gobierno español. Sin embargo, tenemos que partir de la grave herida que ha sufrido el corazón de nuestra sociedad al erradicar la incipiente reflexión sobre el tipo de ciudadano que el español creía ser, o quería llegar a ser.

Una vez reconocido el hecho irreversible de vivir en una sociedad multicultural, la 'interculturalidad' se entrenó durante unos años aprovechando oportunidades y venciendo todo tipo de escollos porque, como construcción intelectual y objetivo social, había llegado enraizada en los Derechos Humanos, en sus valores éticos y morales. La brevedad de esa vorágine cortó su camino de transformación en conocimiento basal de nuestra cultura. Desplazada por las circunstancias históricas de los discursos públicos, es tiempo de que los científicos-sociales avancen con legitimidad en el ámbito iniciado décadas atrás y observen como una ventaja la desvinculación de la interculturalidad' de iniciativas políticas temporales. Pero, sobre todo, es urgente recuperar la formación de los ciudadanos, especialmente de los docentes, para restaurar en nuestra sociedad ese espacio de reflexión sobre los valores que sustentan nuestras conductas, al relacionarnos con los muy diversos otros y con nuestra propia identidad.

Es por eso que saludamos con alegría la aparición de Educación para una ciudadanía intercultural. Cristina Goenechea Permisán y Rafael A. Jiménez Gámez, después de largo tiempo de investigación y experiencia en Educación Intercultural, decidieron exprimir lo hallado, para dar a luz un libro que fuera esencial y útil.

En su introducción, los autores establecen el compro- miso con el lector de no ser "ni asépticos ni neutrales". La lealtad a esas palabras es su clave y atraviesa la obra eliminando la ambigüedad entre las teorías y estrategias que pretenden imponer un modelo mental homogeneizador del individuo y su experiencia vital, y aquellas otras propuestas liberadoras del pensamiento y detonantes de la acción educativa para alcanzar la mejor expresión del ciudadano intercultural. Aun tratándose de un texto académico, se dirige a un público de espectro amplio, y desvelar de forma asequible la arquitectura real de los paradigmas contenidos en su título es uno de sus logros. Otro es ofrecer un compendio de conocimientos bien organizado para dar pasos sólidos en cualquier escenario. La obra se divide en dos partes, la primera, La sociedad multicultural, globalización e inmigración. La construcción de la ciudadanía intercultural, recorre el modo en cómo ciertas perspectivas teóricas han influido en los procesos políticos y económicos que han configurado el mundo en que vivimos. Es el marco precisado por los aportes sociológicos que, a continuación, ayudan a comprender el sistema complejo de factores que han ido transformando el hecho migratorio. Una buena selección de análisis, desde la antropología y otras ciencias sociales, añaden la apertura de los conceptos-herramienta más importantes que nutren la 'interculturalidad' y la 'ciudadanía': multiculturalismo, cultura, diversidad, diferencia, estereotipo, racismo, ciudadanía,... La segunda parte, La acción educativa para una ciudadanía intercultural, evoluciona desde sus cimientos teóricos hasta las experiencias, con una mirada reveladora de los problemas acarreados por el modelo compensatorio y un diagnóstico crítico de la acción intercultural actual, cuando no se halla integrada en una educación verdaderamente inclusiva. Fi- 


\section{I/: Educación para una ciudadanía intercultural}

\section{Reseña}

nalmente, en las arenas de la intervención educativa, realiza una propuesta integra para ser llevada al aula, desde un nuevo enfoque que reconoce y sitúa a los estudiantes como ciudadanos con capacidad pensante y creadora como punto de arranque, y no como objetivo al que llegar, en coherencia con las posiciones y prácticas educativas más avanzadas y con la sensibilidad del horizonte social más deseable para los menores. 